\title{
Farm Mechanization by using Seed Planting Machine
}

\author{
Pradip S. Gunavant ${ }^{1}$, Sarfraj J. Mulani ${ }^{2}$, Vishal N. Gandhe ${ }^{3}$, Gurunath Shinde ${ }^{4}$, Vinayak D Yadav ${ }^{5}$ \\ Assistant Professor, Mechanical Engineering Department, AGTI's Dr. Daulatrao Aher College Engineering, \\ Vidyanagar Extension, Karad, Maharashtra, India ${ }^{1,2,3,4,5}$
}

\begin{abstract}
In the agricultural field, seed planting operation is very time consuming in farming process. Also more labours are required for seed planting. Hence the total cost of the farming increases. The conventional seed sowing machines requires more seed and quantity of seed per unit area increases and this affects the yield. Also conventional seed sowing machines have constraints to use in the ridge and furrow method. But to reduce the risk of draught due to unpredictable rainy season and for irrigation purpose farmers accepts ridge and furrow method. Here in this study efforts are taken to design and develop a seed planting machine which is suitable for ridge and furrow method and also plant the seed at specific distance with specific quantity and reduce the requirement of seed per unit area.
\end{abstract}

Keywords: Seed Mechanization, Sowing, Planting, Ridge and furrow method.

\section{INTRODUCTION}

The India is agricultural country. More than $70 \%$ peoples depend on the agriculture. To improve the economic condition of India, growth in the agricultural sector is important. To achieve this goal efforts are necessary to reduce the cost of farming process by mechanizing the agricultural operations [1].

Manual seed planting is the one of the operation which is very time consuming and more labours are required for this operation. But this method have a drawbacks like low seed placement, variation in spacing and serious back ache for farmers [2][3][4].

Conventional seed sowing method is available but this has a lot of disadvantages like no control over the depth of seed placement, No uniformity in the distribution of seed placement, Loss of seeds, No proper germination of seeds [5]. Also not useful for ridge and furrow method. Conventional seed sowing machines are not suitable for ridge and furrow method and large quantity of seed is necessary.

In this study focus is on to reduce the disadvantages of manual and conventional method and develop a seed planting machine which is suitable to plant seed at specific interval and also useful to plant seed in ridge and furrow method.

\section{PURPOSE OF SEED PLANTER MACHINE}

The objectives of seed planter machine are to put seeds at desired depth with constant seed spacing and covering the seed with soil. This machine is suitable for planting seed in ridge and furrow method, flat arrow method, flat bed method as well as multi cropping. The main objective of this machine is to reduce human effort and back ache of farmers.

\section{PROBLEM IDENTIFICATION}

The following steps are to be taken to identify the problem i. The first step is to go to the farmers and find the problems faced by them.

ii. The second step is to choose a problem.

iii. The third step is to collection of data regarding the seed sowing and planting by farmer interview and literature review.

The drawbacks of existing machines are:

a. The spacing between two seeds are uneven.

b. It requires more than two operators.

c. Flow rate of seeds are not controllable.

After the field visits and literature review we are concluded to work on seed planter machine which nullify the previous machines drawbacks.

\section{SOLUTION METHODOLOGY}

For finding the solution of problem we studied different types of mechanism which is useful and preferable to reduce human effort and above existing machine problems. After comparing the various mechanism and there feasibility we are decided to use scotch and yoke mechanism for seed metering. In existing seed sowing machines impellers are used for seed metering. To take decision regarding row spacing, ridge and furrow dimensions surveying of a nearer farms are carried out. Also survey regarding the standard material and components available is carried out to fix the dimensions of the seed planting machine. After that the seed planting machine model is developed by using CATIA V5R15 software. This model is modified by analysing the various factors like weight of machine assembly, speed of the movement, bending moment of the rod. After that the model is fabricated and field tests are performed. 


\section{IAR JSET}

International Advanced Research Journal in Science, Engineering and Technology

National Conference on Design, Manufacturing, Energy \& Thermal Engineering (NCDMETE-2017) AGTI's Dr. Daulatrao Aher College Engineering, Vidyanagar Extension, Karad

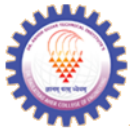

Vol. 4, Special Issue 1, January 2017

\section{DESCRIPTION OF MAJOR COMPONENTS OF THE MACHINE}

\section{A. Frame With Dibber}

The frame provides proper balance to the structure considering the size constraints and it supports the various parts of the machine and mechanisms. Mild steel is used for the frame. The structural dimensions are selected in such a way that the frame can sustain various shocks and loads.

Dibber is a device used to stirring the soil to a greater depth for sowing the seeds.

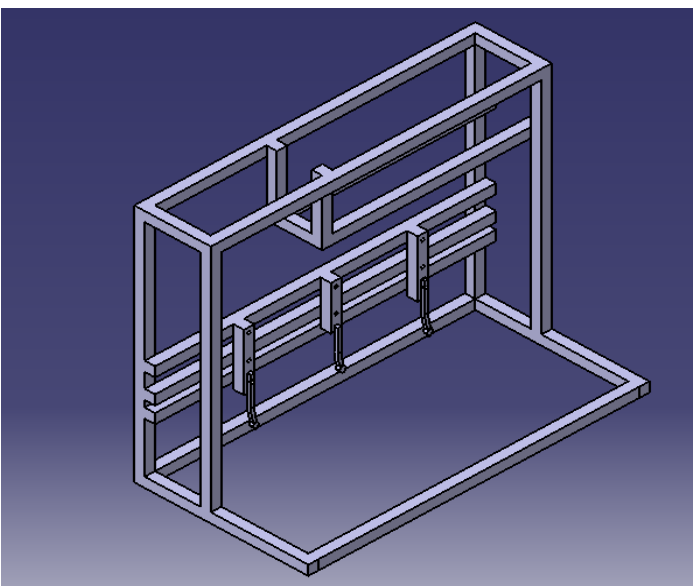

Fig. 1. Frame with dibber

\section{B. Hopper}

Hopper is used to store the different types of seeds. The hopper has adjusting plate to control the seed rate. For different types of seeds, adjusting plate helps to adjust seed rate. Here three hoppers are used in this machine. Multi cropping is possible by using three different seeds for three hopper.

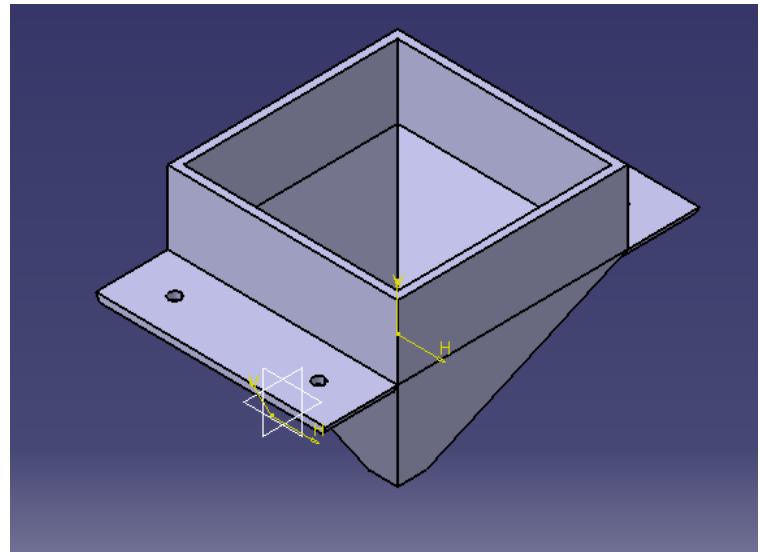

Fig. 2. Hopper

\section{Metallic rod}

Mild steel rod of $16 \mathrm{~mm}$ diameter and $120 \mathrm{~mm}$ length is used to support the wheels balance the total load of machine.

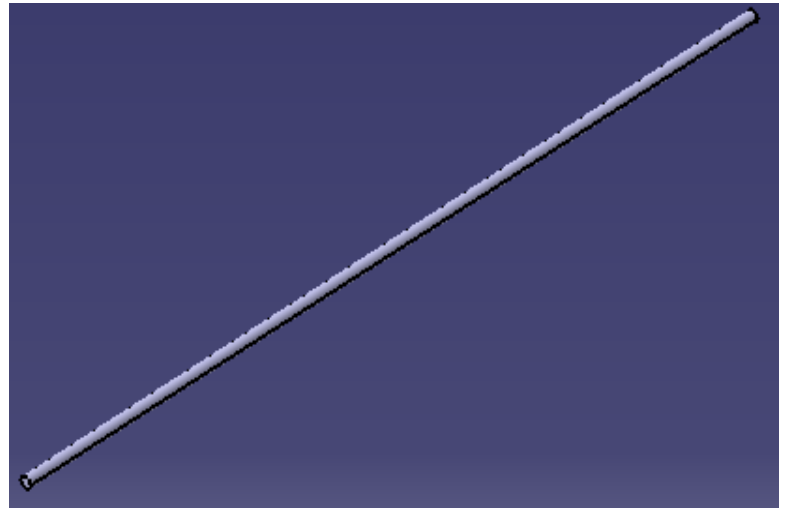

Fig.3. Metallic Rod

\section{Bevel gear assembly}

Bevel gear assembly is used to convert the rotational motion into linear motion. Here 10 tooth bevel gears are used. The material used for bevel gear is cast iron.

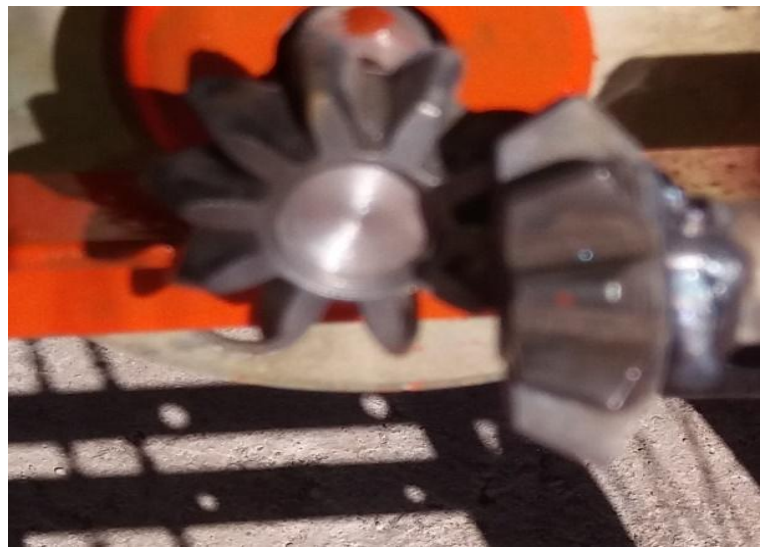

Fig.4. Bevel Gear Assembly

E. Pedestal Bearing

Two Pedestal bearings are mounted on the metallic rod and the frame is fixed on these bearings so that there is connection between rotating rod and the frame.

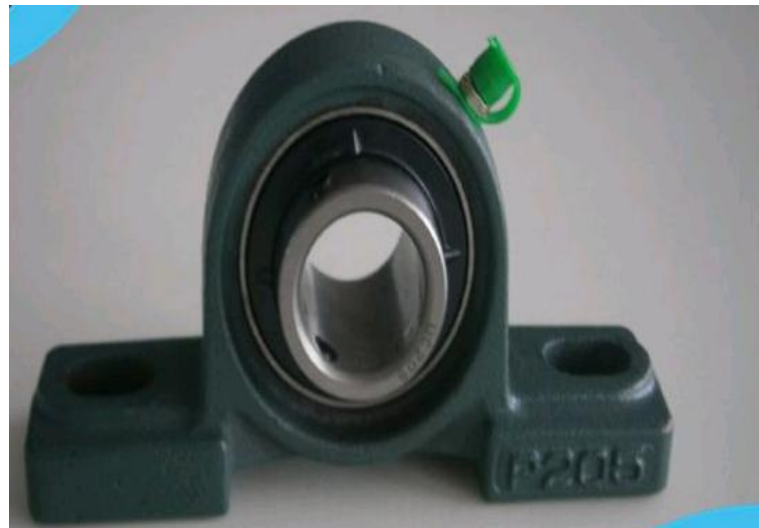

Fig.5. Pedestal Bearing

F. Ball Bearings

Ball bearings are used to mount chain drive on the rods to transmit power to the bevel gear assembly 
IARJSET

Vol. 4, Special Issue 1, January 2017

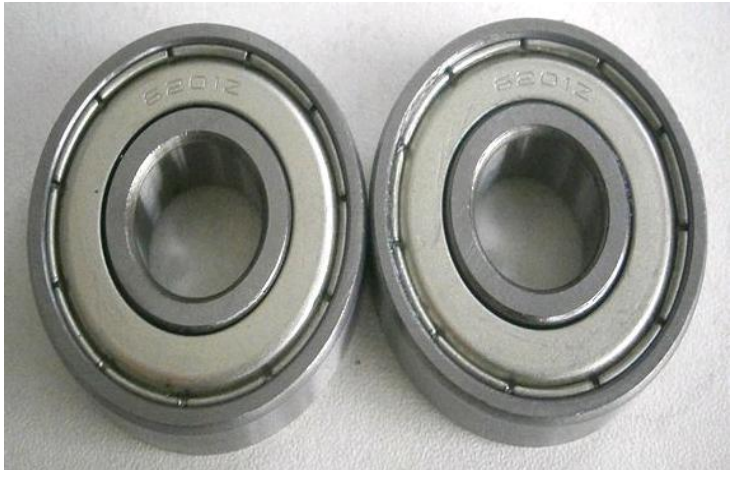

Fig.6. Ball Bearing

\section{G. Chain drive}

Chain drive is used to ensure perfect velocity ratio. To avoid slipping chain drive is used. The chain is mostly used to transmit motion and power from one shaft to another. Chain drive always gives positive drive.

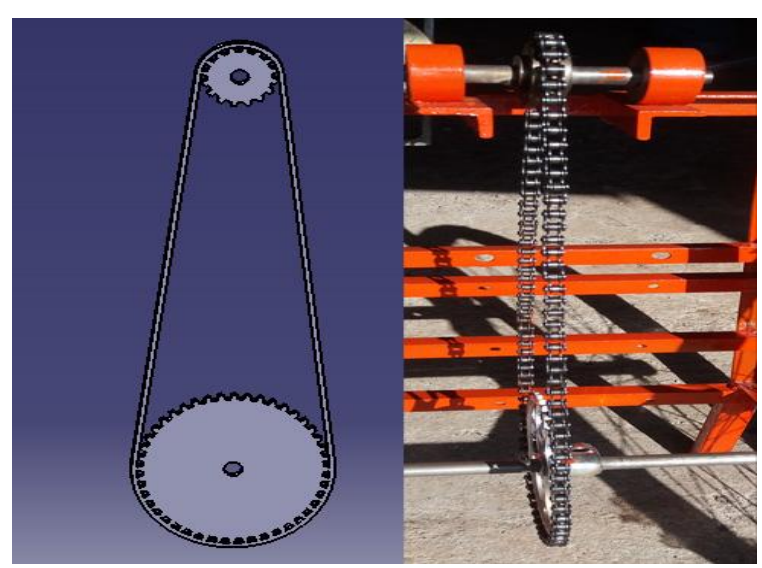

Fig.7. Chain drive

H. Scotch and yoke mechanism

Scotch and yoke mechanism is used to convert rotational motion into linear motion for the seed metering. Also this mechanism gives the constant stroke of linear motion.

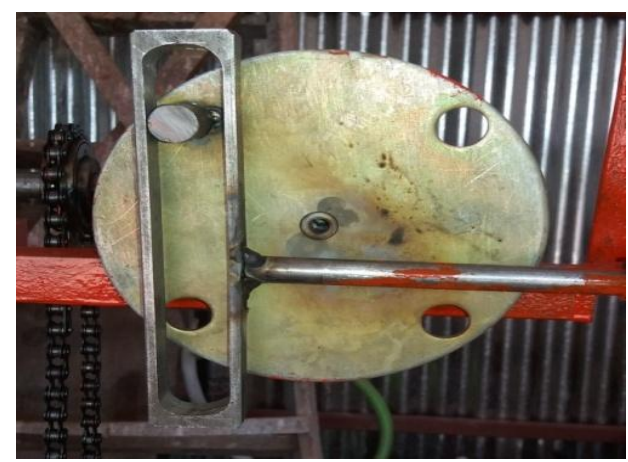

Fig.8. Scotch and Yoke mechanism

\section{FABRICATION OF MACHINE}

I. Frame manufacturing

For the frame manufacturing we select the angle plate of $25 * 25 * 3 \mathrm{~mm}$ of material M.S. As per design angle plate is cut by electric cutting machine and welded by welding machine.

\section{J. Selection of bearing}

After frame manufacturing we fixed the standard bearing. We select the three ball bearing number of $6201 \mathrm{z}$ and two pedestal bearing number of UC204.

\section{K. Wheel assembly}

We select the wheel of suitable diameter on the basis of the survey data. To fit wheel on the shaft, bushes are manufactured and fitted on that metalic rod and wheels are fixed on the bearing.

\section{Manufacturing of dibber}

We have to decide suitable angle for dibber. After that we manufacture dibber of different heights with adjustable hole. With the help of this it is possible to adjust any height and row spacing.For the maintenance purpose also this adjustment is beneficial.

\section{Design and manufacturing of hoppers}

G.I sheet material is selected for hopper and hopper is designed in such away that it can handle of $2 \mathrm{~kg}$ capacity seeds. We cut the sheet on shearing machine as per the design. Hoppers are then manufactured by welding process. At the bottom of the hopper a box type outlet is prepared for the flow of seeds.

\section{N. Seed metering mechanism}

In seed metering mechanism we make the stoppers to avoid the continuous flow of seeds. One fixed plate is attached to the frame below the hopper, the flexible pipe attached in between hopper and inlet of the dibber. It transfers the seeds from hopper to the ground.

O. Seed regulating mechanism

Seed regulating mechanism regulates the flow of seed. For that purpose we make the movable strip which is connect to the scotch yoke mechanism and other one plate is fixed to the frame.

\section{P. Scotch yoke mechanism}

It is the main working mechanism of this seed planting machine. The yoke material is mild steel of $16 \mathrm{~mm}$ width and 168 depth. It is manufactured by milling machine. For scotch we select the one disk of diameter $160 \mathrm{~mm}$ and it is drilled at centre of the disk.

\section{Q. Transmission system}

The power is transmitted from wheel to the mechanism we select two gear and chain drive on the basis of gear ratio. The no of teeth on big gear is 44 and on small gear is 16 and the centre to centre distance between two gear is $465 \mathrm{~mm}$.

\section{R. Bevel gear assembly}

We select the 2 pedestal bearing for shaft support and also three ball bearings are used at the scotch yoke mechanism. 


\section{IAR JSET}

International Advanced Research Journal in Science, Engineering and Technology

National Conference on Design, Manufacturing, Energy \& Thermal Engineering (NCDMETE-2017)

AGTI's Dr. Daulatrao Aher College Engineering, Vidyanagar Extension, Karad

Vol. 4, Special Issue 1, January 2017

Two bevel gears of same teeth are used to change the vertical motion of the shaft into horizontal motion. The completely fabricated seed planting machine is shown in Fig.9.

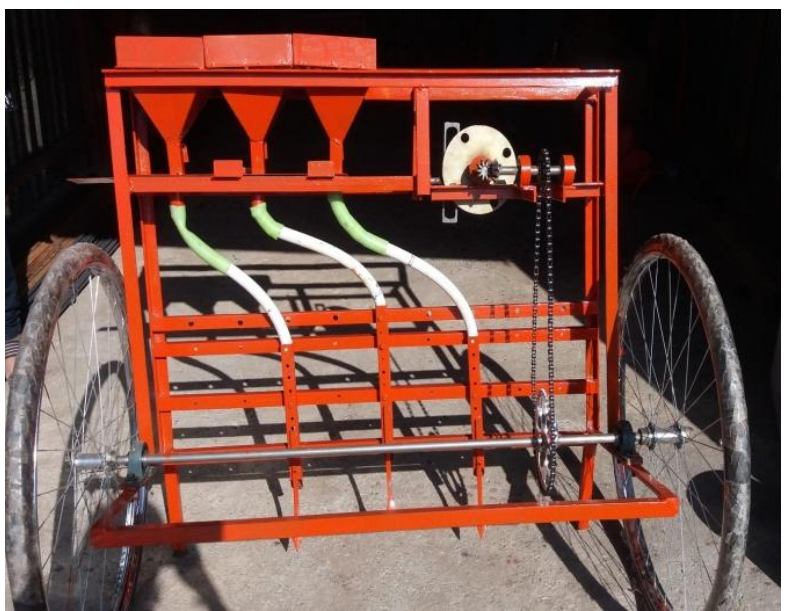

Fig.9. Assembly of seed planting machine

\section{WORKING OF THE MACHINE}

The working of the seed planter machine is described as follows:

When the force applied by the farmer on the handle of the seed sowing machine then the wheels are move towards forward direction. The wheels start to rotate with some specific rotation. Wheels are mounted on the metallic rod which is also rotates in the direction of wheels.

Also the sprockets are mounted on the metallic rod which transmit the rotating motion of the wheel to the shaft of the bevel gear. Here, the chain drive is used to smooth transmission of the motion of the wheel to the bevel gear assembly.

Bevel gears are used to the transmission of motion in perpendicular axis. For these bevel gears are connected perpendicular to each other. The function of the bevel gear is to transmit motion in perpendicular direction with same speed.

On the shaft of the second bevel gear scotch and yoke mechanism is mounted transmits linear motion to the strip which controls the seed rate by opening and closing the hopper outlets. Strip stars to reciprocate with constant stroke by this mechanism. The seeds are stored in the hopper as per requirement. The flow of these seeds in the downward direction takes place due to gravity. When the strip reciprocates with constant intervals the holes of the strip and the hopper are gets matches and seeds flow through the holes. These flowing seed moves in the flexibal pipes and after that it comes in the back side of the dibber and sows in the soil. After that seeds are covered by triangular strip which is mounted back side of the dibber hole.

\section{CONCLUSIONS}

We have developed a seed planter machine which will meet the farmer requirements using the determined engineering specifications. The following is a final summary of what we did and how we went about it.

Stability, comfort and hand control were determined to be the most important requirements. All these requirements have been used in developing our concepts and have been implemented in our model.

We developed and followed through with a fabrication plan that produced a working product. This plan gave a detailed description of the process needed if our work is to be replicated. The final design has been broken down into five subsections: Frame, Dibber, Hopper, transmission system and scotch yoke mechanism. We created each of these sub sections separate in the machine shop and fabricated these. We then assembled these sections together and created our final model.

\section{FUTURE SCOPE}

It is necessary to give top priority for safety operation, Cost reduction. It is necessary improve the strength of the machine members such as dibber. Presently, full focus is given only to design modification in seed metering mechanism which is beneficial to the small farmers. At present, seed metering mechanism is used for sowing different types of seeds with single metering mechanism. In future further study is needed to use separate metering mechanism for every seeds. Thus, we can increase the value of the machine in future. By using electrical drive, the machine can be made automatic just like an automobile which can faster the work of seed planting. It can be also used for planting as well as fertilizer sowing. In future, it is possible to use the electronic operated solenoid valve to maintain the seed flow rate. It is time operated valve. Also we will use level sensors to know the level of seeds and maintain it.

\section{ACKNOWLEDGMENT}

The authors would like to express sincere gratitude to AGTI's Dr. Daulatrao Aher College Engineering, Karad, Satara, India for their help and support.

\section{REFERENCES}

[1] Kalay Khan, Dr. S. C. Moses, The Design and Fabrication of a Manually Operated Single Row Multi - Crops Planter, IOSR Journal of Agriculture and Veterinary Science (IOSR-JAVS) Volume 8, Issue 10 Ver. II PP 147-158,Oct. 2015

[2] A. R. Kyada and D. B. Patel, Design And Development Of Manually Operated Seed Planter Machine, 5th International \& 26th All India Manufacturing Technology, Design and Research Conference (AIMTDR 2014)2014, IIT Guwahati, Assam, India,Dec 2014. 
[3] Roshan V. Marode, Gajanan P .Tayade, Design And Implementation Of Multi Seed Sowing Machine, IJMERR, Vol. 2, No. 4, October 2013

[4] D.Ramesh and H.P. Girishkumar, Agriculture Seed Sowing Equipments: A Review, International Journal of Science, Engineering and Technology Research (IJSETR), Volume 3, Issue 7, July 2014

[5] Nilesh N. Jadhav, Harshal R. Aher et. al. Design and Fabrication of Onion Seed Sowing Machine, International Journal on Recent Technologies in Mechanical and Automobile Engineering (IJRMAE) Volume: 2 Issue: 6,June 2015

\section{BIOGRAPHIES}

Pradip S. Gunavant has received his bachelors and masters degree in Mechanical Heat Power Engineering from Shivaji University, Kolhapur. Presently he is working as Assistant Professor in Mechanical Engineering department at AGTI's Dr. Daulatrao Aher College Engineering, Karad. His research areas of interest are Design, farm mechanization, CFD, Fluid mechanics and Heat transfer.

Sarafaraj J. Mulani has received his bachelors and masters degree in Mechanical Production Engineering from Shivaji University, Kolhapur. Presently he is working as Assistant Professor in Mechanical Engineering department at AGTI's Dr. Daulatrao Aher College Engineering, Karad.His research areas of interest are Design, Manufacturing, Mechatronics.

Vishal N. Gandhe has received his bachelors and masters degree in Mechanical Production Engineering from Shivaji University, Kolhapur. Presently he is working as Assistant Professor in Mechanical Engineering department at AGTI's Dr. Daulatrao Aher College Engineering, Karad. His research areas of interest are Refrigeration and Air Conditioning, Manufacturing.

Gurunath V. Shinde has received his Bachelors and Masters Degree in Mechanical-Production Engineering from Shivaji University, Kolhapur. Presently he is working as Assistant Professor in Mechanical Engineering department at AGTI's Dr. Daulatrao Aher College Engineering, Karad. His research areas of interest are advanced manufacturing processes, finite element analysis and optimization techniques.

Vinayak D. Yadav has received his bachelors and masters degree in Mechanical Production Engineering from Shivaji University, Kolhapur. Presently he is working as Assistant Professor in Mechanical Engineering department at AGTI's Dr. Daulatrao Aher College Engineering, Karad. His research areas of interest are Finite Element Analysis, Advanced Manufacturing Processes. 